\title{
Studying End of Life Conversations: Challenges and Strategies
}

\author{
Phyllis Whitehead*, PhD, APRN/CNS, ACHPN, PMGT-BC, FNAP \\ Palliative Medicine Clinical Nurse Specialist and Clinical Ethicist, Carilion Roanoke Memorial Hospital, Virginia Tech Carilion School of Medicine, USA
}

${ }^{*}$ Corresponding author: Phyllis Whitehead, Carilion Roanoke Memorial Hospital, Virginia Tech Carilion, School of Medicine, Roanoke, VA, USA; Email: pbwhitehead@carilionclinic.org

Received: May 21, 2021; Accepted: May 28, 2021; Published: June 04, 202

End-of-life (EOL) conversations continue to be challenging for patients, families, and healthcare providers (HCPs) [1-3]. Although these dialogues can be emotionally charged, they are critical to ensure that care is aligned with patient preferences. Interventions directed at improving communication about EOL care have been shown to improve patient outcomes. Nurses are in a unique position to assist patients and families with advocating for EOL conversations [4,5]. Advance care planning studies are prominent in EOL literature with the intent of clarifying life sustaining treatment preferences of patients. Unfortunately, most EOL decisions are still made without direct input from patients but rather loved ones are burdened with deciding whether or not to continue life sustaining interventions. In addition, family members report that they were unaware of their loved ones wishes and values with all of the treatment options [6]. More research is needed to develop practical approaches and strategies to enhance EOL conversations to properly align patients' priorities of care. But conducting these studies remains challenging.

Challenges: First, recruitment can be extremely problematic if the study is targeting patients with specified prognosis. Most HCPs are uncomfortable and lack the knowledge to prognosticate accurately. They are uncomfortable with approaching eligible patients. Additionally, due to variability in patient conditions, availability of patients due to treatments and tests, it is often difficult to schedule interviews. Loved ones are often unavailable during the regular daytime hours. Nurse and HCPs are frequently busy caring for patients. The interviewers are often faculty university members with busy teaching and/or clinical schedules. Other challenges of clinician and stakeholder engagement include the struggle to find convenient, uninterrupted interview times for patients, loved ones and nurses. Furthermore, even if the above challenges are overcome, the interviewers may have discomfort in initiating EOL discussions with both patients and loved ones. Strategies: With the proper study inclusion criteria education and support from more confident, experienced colleagues, nurses can be coached to identify appropriate participants for EOL research. Providing a script to begin the conversations has been shown to be valuable. EOL investigators should expect participant recruitment challenges and plan for ongoing education and support of referral staff. Researchers should plan regularly scheduled debriefing sessions with interviewers to provide emotional support and encouragement to minimize distress. Allocating resources to infuse research into the workplace should involve flexible staffing for participant referral identification and time allocation for interviews of patients and nurses. Providing a scripted approach such as the Patient Preferences About Serious Illness (PASI) [7-9] to introduce the topic may ease HCPs discomfort and allows patients the opportunity to have open, honest dialogues. Ultimately, ongoing discussions between the patient, loved ones and HCPs are the goal throughout the course of the serious illness. More research is needed to improve the process of eliciting EOL discussions between patients and their HCPs and in designing tools such as the PASI. By acknowledging and anticipating the difficulties of having honest EOL dialogues, researchers can tailor strategies to minimize the barriers while promoting opportunities to engage patients, loved ones and HCPs.

\section{References}

1. Trachsel M, Irwin SA, Biller-Andorno N, Hoff P, Riese F (2016) Palliative psychiatry for severe persistent mental illness as a new approach to psychiatry? Definition, scope, benefits, and risks. BMC Psychiatry 16: 1-7.

2. Scott J, Owen-Smith A, Tonkin-Crine S, Hugh Rayner, Paul Roderick, et al. (2018) Decision-making for people with dementia and advanced kidney disease: A secondary qualitative analysis of interviews from the Conservative Kidney Management Assessment of Practice Patterns Study. BMJ Open 8. [crossref]

3. Abdul-Razzak A, Heyland DK, Simon J, Ghosh S, Day AG, You JJ (2019) Patientfamily agreement on values and preferences for life-sustaining treatment: results of a multicentre observational study. BMJ Support Palliat Care 9. [crossref]

4. Torke AM, Hickman SE, Hammes B, Steven R Counsell, Lev Inger, et al. (2019) POLST Facilitation in Complex Care Management: A Feasibility Study. Am J Hosp Palliat Med. 36: 5-12. [crossref]

5. Shaw M, Shaw J, Simon J (2020) Listening to Patients' Own Goals: A Key to Goals of Care Decisions in Cardiac Care. Can J Cardiol. 36: 1135-1138. [crossref]

6. Foglia MB, Lowery J, Sharpe VA, Tompkins P, Fox E (2019) A Comprehensive Approach to Eliciting, Documenting, and Honoring Patient Wishes for Care Near the End of Life: The Veterans Health Administration's Life-Sustaining Treatment Decisions Initiative. Jt Comm J Qual Patient Saf 45: 47-56. [crossref]

7. Whitehead PB, Clark RC (2016) Addressing the challenges of conducting research with end-of-life populations in the acute care setting. Appl Nurs Res. 30: 12-15. [crossref] 
Phyllis Whitehead (2021) Studying End of Life Conversations: Challenges and Strategies

8. Whitehead PB, Carter KF (2017) A model for meaningful conversation in serious illness and the patient preferences about serious illness instrument. J Hosp Palliat Nurs. 19.
9. Whitehead PB, Ramalingam N, Carter KF, Katz K, Harden S (2016) Nurse practitioners' perspectives on the patient preferences about serious illness instrument. $J$ Hosp Palliat Nurs. 18

\section{Citation:}

Whitehead P (2021) Studying End of Life Conversations: Challenges and Strategies. Integr J Nurs Med Volume 2(2): 1-2. 